\title{
Angiotensin Receptor Blockers in cyclodextrin nanoparticle eye drops: Ocular pharmacokinetics and pharmacologic effect on intraocular pressure
}

\author{
Laura Lorenzo-Soler, ${ }^{1}$ (D) Olof Birna Olafsdottir, ${ }^{1,2,3}$ Gerhard Garhöfer, ${ }^{4}$ Phatsawee Jansook, \\ Iris Myrdal Kristinsdottir, ${ }^{3}$ Aimin Tan, ${ }^{6}$ Thorsteinn Loftsson $^{7}$ and Einar Stefansson ${ }^{1,2,3}$ \\ ${ }^{1}$ Faculty of Medicine, University of Iceland, Reykjavík, Iceland \\ ${ }^{2}$ Department of Ophthalmology, Landspitali University Hospital, Reykjavík, Iceland \\ ${ }^{3}$ Oculis ehf., Reykjavík, Iceland \\ ${ }^{4}$ Department of Clinical Pharmacology, Medical University of Vienna, Vienna, Austria \\ ${ }^{5}$ Faculty of Pharmaceutical Sciences, Chulalongkorn University, Bangkok, Thailand \\ ${ }^{6}$ Nucro-Technics, Toronto, ON, Canada \\ ${ }^{7}$ Faculty of Pharmacy, University of Iceland, Reykjavík, Iceland
}

\begin{abstract}
.
Purpose: Orally administered angiotensin II receptor blockers (ARBs) decrease intraocular pressure (IOP). Topical administration may reduce systemic side effects and result in a useful glaucoma drug. The aim of this study is to test the ocular delivery and pharmacologic effect of nanoparticle eye drops containing ARBs (e.g. irbesartan and candesartan).

Methods: $1.5 \%$ irbesartan and $0.15 \%$ candesartan eye drops were applied to rabbits. The pharmacokinetics in cornea and aqueous humour after single eye drop application were studied in 49 rabbits. The effect of the eye drops on IOP was studied in 10 rabbits using an iCare ( ${ }^{\circledR}$ TonoVet Plus, iCare, Finland) tonometer and compared with $\mathbf{0 . 5 \%}$ timolol eye drops.

Results: Candesartan lowered IOP from $24.6 \pm 5.1 \mathrm{mmHg}$ at baseline to $19.0 \pm 2.9 \mathrm{mmHg}$ (mean $\pm \mathrm{SD}, \mathrm{p}=\mathbf{0 . 0 3 0}, n=10) 4 \mathrm{hr}$ after application. Irbesartan lowered IOP from $24.2 \pm 1.7 \mathrm{mmHg}$ to $20.2 \pm 0.9 \mathrm{mmHg}$ $(p=0.14, n=10)$. Timolol decreased the IOP from $24.9 \pm 4.2 \mathrm{mmHg}$ to $20.4 \pm 4.8 \mathrm{mmHg}$ (mean $\pm \mathrm{SD}, \mathrm{p}=\mathbf{0 . 0 3 6}, n=10)$. The pharmacokinetics data show that both formulations deliver effective amounts of drug into the intraocular tissues, with irbesartan and candesartan reaching concentrations of $121 \pm 69$ and $30.43 \pm 13.93 \mathrm{ng} / \mathrm{g}$ (mean $\pm \mathrm{SD}$ ), respectively, in the aqueous humour $3 \mathrm{hr}$ after a single-dose administration.

Conclusions: Topical application of irbesartan and candesartan eye drops delivers effective drug concentrations to the anterior segment of the eye in rabbits, achieving drug concentrations 100 times above the IC50 for angiotensin II receptor and showing an IOP-lowering effect. Angiotensin receptor blocker (ARB) eye drops have potential as a new class of glaucoma drugs.
\end{abstract}

Key words: angiotensin receptor blockers - glaucoma - intraocular pressure - pharmacokinetics

Acta Ophthalmol.

(๑) 2020 Acta Ophthalmologica Scandinavica Foundation. Published by John Wiley \& Sons Ltd

doi: $10.1111 /$ aos. 14639

\section{Introduction}

The renin-angiotensin system (RAS) plays a role in aqueous humour secretion. The presence of RAS components, as well as enzyme activities of angiotensin-converting enzyme (ACE), have been reported in the eye of several species including human, suggesting that local ocular RAS is involved in the regulation of IOP (Holappa et al., 2020). The primary mechanism of action of an angiotensin receptor blocker (ARB) involves selectively blocking the binding of angiotensin II (Ang II) to the angiotensin type I receptor. This affects the aqueous humour formation signalling process and reduces IOP by decreasing aqueous humour production (Van Haeringen, 1996; Campbell, 2014).

While current glaucoma eye drops are effective in lowering IOP, each has local or systemic side effects, that limit their use. Beta-blockers affect respiratory and cardiac function and prostaglandin analogs and carbonic anhydrase inhibitors show potential eye irritation (Inoue, 2014). This is especially limiting for patients who need multiple drugs to control IOP. This group of patients will benefit from the option of new classes of glaucoma drugs, especially if they have little or no side effects, such as cough, low blood 
pressure, headache, rashes and indigestion.

Angiotensin-converting enzyme (ACE) inhibitors (ACE-I) have also been shown to lower IOP by inhibiting the formation of Ang II and thereby reducing the stimulation of angiotensin type I receptors. However, the production of Ang II can occur through nonACE pathways which remain unaffected by ACE inhibition (Brunner, 2007). Moreover, ARBs show some advantages over ACE-I, including an absence of significant adverse reactions and a favourable side effect profile (Al Sabbah et al., 2013).

Eye drops are the preferred route of ocular drug administration, but the bioavailability of topically applied formulations is limited by the various protective mechanisms and barriers of the eye (Patel et al., 2013). Furthermore, the physicochemical properties of ARBs and ACE inhibitors, such as poor aqueous solubility and instability in aqueous solutions, have prevented their formulation and use as clinically effective eye drops (Chiang, Ho, \& Chen, 1996; Agarwal et al., 2014; Muankaew et al., 2014). Our group has now solved this with a novel formulation based on cyclodextrin nanoparticles. Cyclodextrins enable formulation of lipophilic poorly soluble drugs as aqueous eye drop solutions increasing their bioavailability by enhancing drug permeation through the aqueous tear film and eye wall (Jansook et al., 2015).

The $\gamma$-cyclodextrin nanoparticle technology was used to develop $1.5 \%$ $(\mathrm{w} / \mathrm{v})$ irbesartan and $0.15 \%(\mathrm{w} / \mathrm{v})$ candesartan microsuspension eye drop formulations (Jansook et al., 2015).

The aims of this study are (1) to examine the pharmacokinetics of irbesartan and candesartan in $\gamma$-cyclodextrin nanoparticle eye drops in the anterior segment of the rabbit eye and (2) test the hypothesis that irbesartan and candesartan eye drops lower IOP in rabbits.

\section{Materials and methods}

\section{Ethical statement}

This research followed the ARVO Statement for the Use of Animals in Ophthalmic and Vision Research. For the IOP study, professional assistance by veterinarians at the Institute for
Experimental Pathology from the University of Iceland was provided and approval by the Icelandic Food and Veterinary Authority (MAST) was obtained. The pharmacokinetics study was approved by the local animal welfare committee (GZ BMWFW$66.009 / 0163-\mathrm{V} / 3 \mathrm{~b} / 2018)$.

\section{Animals}

59 New Zealand rabbits (Oryctolagus cuniculus; weight, 3.0-6 kg) were used in studies. 10 rabbits were used in the IOP study and 49 rabbits (26 for irbesartan and 23 for candesartan) were used in the pharmacokinetic study. They were housed in groups by two in cages with raised areas, kept under controlled, standardized conditions (artificial L/D cycle 12:12, room temperature $22 \pm 2{ }^{\circ} \mathrm{C}$, humidity $55 \pm 10 \%$ ) and had ad libitum access to complete feed for rabbits. They were acclimatized for a minimum of 7 days.

The rabbits were not anaesthetized during the procedures and no topical agent was used before the eye drops administration.

\section{Test compounds}

$1.5 \%$ irbesartan, $0.15 \%$ candesartan and vehicle eye drops in $\gamma$-cyclodextrin nanoparticle suspensions were tested. The difference in concentration for the two ARBs is due to solubility and stability. The formulations have been described previously (Jansook et al., 2015). The eye drops were placed into a sonicator at $40^{\circ} \mathrm{C}$ for $30 \mathrm{~min}$ and shaken thoroughly until homogenously suspended immediately before eye drops administration to the rabbits (Muankaew et al., 2014). After use, they were stored at controlled room temperature $\left(\sim 25^{\circ} \mathrm{C}\right)$ and protected from light.

For the IOP study, a commercial $0.5 \%$ timolol solution (Optimol, Oftan, Japan) was also tested, administering the eye drops directly from the vial.

\section{Intraocular pressure study}

Ten rabbits were tested repeatedly with five different drugs or controls in eye drop applications with one application per day (treatment 1: $0.15 \%$ candesartan, treatment $2: 1.5 \%$ irbesartan, treatment 3: $0.5 \%$ timolol, treatment 4: blank, treatment 5: vehicle). $50 \mu$ of each suspension was topically administered to the left eye of each rabbit using a pipette. Timolol solution was administered as one drop directly from the vial. The blank group received no treatment. A minimum of a 2-day washout period was observed between study days.

Four measurement time-points were established for each treatment group: baseline (right before eye drop administration), $1 \mathrm{~min}, 2 \mathrm{hr}$ and $4 \mathrm{hr}$ after administration. Baseline and one minute after administration measurements were averaged due to the closeness of values and time-points. Intraocular pressure (IOP) was measured only on the left eye (treated eye) using a rebound tonometer $\left({ }^{\circledR}\right.$ TonoVet Plus, iCare, Finland) and IOP measurements were taken at the same time of the day for all groups to minimize fluctuations due to circadian rhythm. All ten rabbits were tested with all study drugs and controls at different times.

\section{Pharmacokinetic study}

A total of 49 animals were used, 26 rabbits for irbesartan and 23 for candesartan, and $35 \mu$ of the ophthalmic solution was administered into the conjunctival sac of the (left) study eye of each rabbit with no drug application to the fellow eye. Rabbits were euthanized in anaesthesia (ketamine $60 \mathrm{mg}$ / $\mathrm{kg}$, xylazine $16 \mathrm{mg} / \mathrm{kg}$, s.c.) by an overdose of pentobarbitone sodium at five predefined time-points $(0.5 \mathrm{~h}, 1.5 \mathrm{~h}$, $3 \mathrm{~h}, 6 \mathrm{~h}, 12 \mathrm{~h})$ after drug administration. Immediately after euthanasia, both eyes were enucleated from each animal. The study eye demonstrates the combination of topical and systemic absorption, whereas the fellow eye shows systemic absorption alone. Enucleated eyes were frozen immediately and stored at $-80^{\circ} \mathrm{C}$ until further processing. For separation of the different ocular tissues, the eyeball was removed from storage and dissected into different parts: cornea, aqueous humour, vitreous body and the retina/ choroid, each of which was stored separately in different tubes. All tissues were collected and separately weighted upon collection and stored in separated tubes. Tissue samples including aqueous humour, cornea, retina and vitreous were sent to Nucro-Technics (Scarborough, Ontario, Canada) for assessment of the study drug concentrations. 
Weighed rabbit eye tissue samples were homogenized in $\mathrm{H}_{2} \mathrm{O}$-diluted rabbit plasma (rabbit plasma/water, 1/14, $\mathrm{v} / \mathrm{v}$ ) in a ratio of $1-19$ (i.e. $1 \mathrm{~g}$ or $1 \mathrm{ml}$ of rabbit eye tissue in $19 \mathrm{ml}$ of diluted rabbit plasma. A $200 \mu \mathrm{l}$ aliquot of rabbit tissue homogenate supernatants was mixed sequentially with $100 \mu \mathrm{l}$ of internal standards $(8 \mathrm{ng} / \mathrm{ml}$ of candesartan- $\mathrm{d}_{4}$ and $20 \mathrm{ng} / \mathrm{ml}$ of irbesartan- $\mathrm{d}_{4}$ in methanol/water $(20 / 80, \mathrm{v} / \mathrm{v})$ and $2 \mathrm{ml}$ of water). The mixtures were then loaded onto the preconditioned HLB cartridges (Waters Oasis ${ }^{\circledR} 60 \mathrm{mg}$, $3 \mathrm{cc}$ ). The cartridges were first washed with $2 \mathrm{ml}$ of methanol/water $(10 / 90, \mathrm{v} /$ v) and then eluted with $2 \mathrm{ml}$ of methanol. The organic solvents were evaporated at $40^{\circ} \mathrm{C}$ and the dry residues were reconstituted in $200 \mu 1$ of methanol/water/formic acid (70/29.75/ $0.25, \mathrm{v} / \mathrm{v} / \mathrm{v})$.

An Agilent 1200 series liquid chromatograph coupled with an Agilent 6490 Triple Quad LC/MS (Agilent Technologies Canada, Mississauga, Ontario, Canada) was used for the LCMS/MS analysis. A $20 \mu \mathrm{l}$ aliquot of the extracted samples was injected onto an ACE Excel 5 Super C18 column $(4.6 \times 150 \mathrm{~mm}$, Advanced Chromatography Technologies, Aberdeen, Scotland) maintained at $25^{\circ} \mathrm{C}$ for a gradient separation at the flow rate of $0.8 \mathrm{ml} / \mathrm{min}$. The mobile phase A was methanol $/ \mathrm{H}_{2} \mathrm{O} /$ formic acid, 70/29.75/ $0.25(\mathrm{v} / \mathrm{v} / \mathrm{v})$ and the mobile phase $\mathrm{B}$ was methanol $/ / \mathrm{H}_{2} \mathrm{O} /$ formic acid, 90/ $9.75 / 0.25(\mathrm{v} / \mathrm{v} / \mathrm{v})$. For gradient elution, $100 \%$ mobile phase A was used for the first $4.5 \mathrm{~min}$, followed by $100 \%$ mobile B for $1.5 \mathrm{~min}$, and then back to $100 \%$ mobile phase A for 2 min of re-equilibration, with a total run time of $8 \mathrm{~min}$. Candesartan and candesartan- $\mathrm{d}_{4}$ were eluted at $5.1 \mathrm{~min}$ and irbesartan and irbesartan- $\mathrm{d}_{4}$ were eluted at $4.1 \mathrm{~min}$. The MS detection was in the positive electrospray ionization (ESI) mode using the MRM transitions (protonated molecule to product ion) of $\mathrm{m} / \mathrm{z}$ $441 \rightarrow 263,445 \rightarrow 267,429 \rightarrow 207$, and $m / z 433 \rightarrow 211$ for candesartan, candesartan- $\mathrm{d}_{4}$, irbesartan, and irbesartan- $\mathrm{d}_{4}$, respectively.

\section{Statistical analysis}

For the statistical analysis regarding IOP measurements data, GraphPad Prism 8.0 for Windows (GraphPad, California, USA) was used and t-test analysis was applied to compare the groups, the significance level was set at $\mathrm{p}<0.05$.

\section{Results}

\section{Intraocular pressure}

Figure 1A shows the individual values for each rabbit in the different groups and the mean change in IOP $(\mathrm{mmHg}$; mean $\pm \mathrm{SD}$ ) for each group, from baseline to $4 \mathrm{hr}$ after administration. Candesartan showed an IOP-lowering effect, from $24.6 \pm 1.6 \mathrm{mmHg}$ at baseline to $19 \pm 0.9 \mathrm{mmHg} \quad(n=10$; change of $5.6 \mathrm{mmHg}) 4 \mathrm{hr}$ postinstillation (paired $t$-test, $\mathrm{p}=0.030$ ).

Irbesartan decreased the IOP from $24.2 \pm 1.7 \mathrm{mmHg}$ to $20.2 \pm 0.9 \mathrm{mmHg}$ $(n=10$; change of $4.0 \mathrm{mmHg}) 4 \mathrm{hr}$ after the eye drops administration (paired $t$ - test, $\mathrm{p}=0.142$ ). For timolol, the observed change in IOP was from $24.9 \pm 4.2 \mathrm{mmHg}$ to $20.4 \pm 4.8 \mathrm{mmHg}$ ( $n=10$, change of $4.6 \mathrm{mmHg}$ ) $4 \mathrm{hr}$ after eye drops administration (paired $t$-test, $\mathrm{p}=0.036$ ).

Figure 1B shows the change in IOP at different measured time-points. The highest changes in IOP for both candesartan and irbesartan occur between 2 and $4 \mathrm{hr}$ after administration. Candesartan showed a change of $1.8 \mathrm{mmHg}$ in the first $2 \mathrm{hr}$ of administration and a $3.7 \mathrm{mmHg}$ change from 2 to $4 \mathrm{hr}$ after administration. Irbesartan lowered the IOP by $0.48 \mathrm{mmHg}$ during the first $2 \mathrm{hr}$ after administration and by $4.5 \mathrm{mmHg}$ from 2 to $4 \mathrm{hr}$ after administration.

On the other hand, timolol shows a more relevant IOP change during the first $2 \mathrm{hr}$ of administration, lowering it

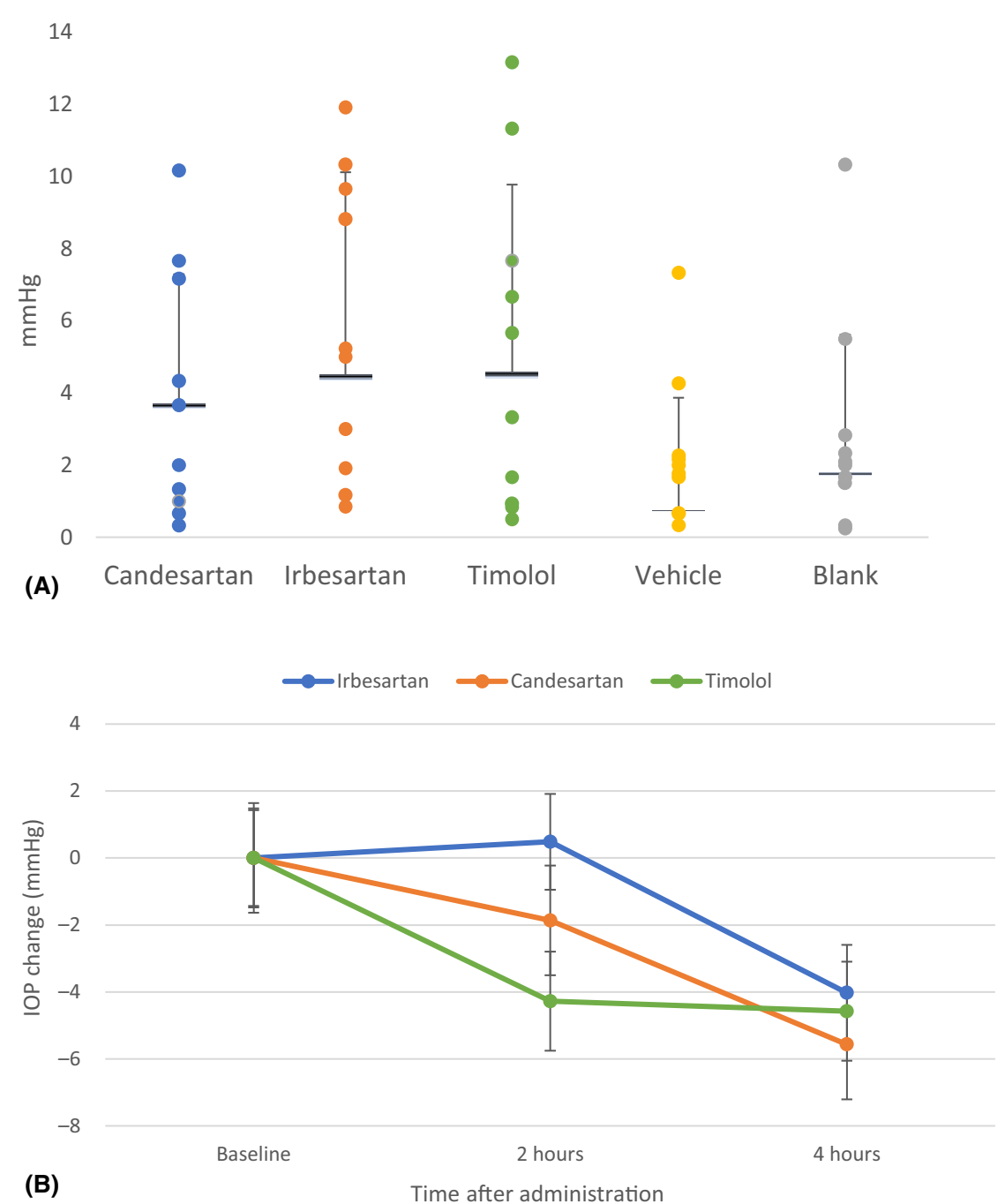

Fig. 1. (A) Mean ( $\mathrm{mmHg}$, mean $\pm \mathrm{SD}$ ) and individual values for IOP change for each of the different drug and control groups $4 \mathrm{hr}$ after eye drop application. (B) IOP change (mmHg, mean $\pm \mathrm{SD}, n=10$ ) at different time-points after eye drop administration for each drug. 
by $4.3 \mathrm{mmHg}$ compared with a change of $0.3 \mathrm{mmHg}$ from 2 to $4 \mathrm{hr}$ after administration.

\section{Pharmacokinetics}

The data from the pharmacokinetic study regarding tissue distribution of both drugs in the cornea and aqueous humour at different time-points after administration $(0.5,1.5,3,6$ and $12 \mathrm{hr})$ is shown in Figs 2 and 3.

For the purpose of the study, which is to evaluate the effectiveness of both drugs as IOP-lowering treatments, only pharmacokinetic data regarding the anterior segment of the eye are shown. Irbesartan reached a maximum concentration of $282 \pm 159 \mathrm{nM}$ (mean $\pm \mathrm{SD}, n=26$ ) in the aqueous humour of the study eye $3 \mathrm{hr}$ after administration (Fig. 2A) and candesartan's maximum concentration in the aqueous humour was $70 \pm 73 \mathrm{nM}$ (mean $\pm \mathrm{SD}, n=23) 3 \mathrm{hr}$ after administration (Fig. 3A).

\section{Discussion}

Our data demonstrate that irbesartan and candesartan in $\gamma$-cyclodextrin nanoparticle eye drops penetrate the rabbit eye in pharmacologically relevant concentrations after a single topical application and lower IOP comparably to timolol eye drops. Several publications support the efficacy of ARBs and ACEs as IOP-lowering treatments. Relevant studies and their results are listed in Table 1.

Based on a study from Kim et al., the IC50 of irbesartan as an angiotensin II type 1 receptor-specific competitive antagonist is $1.3 \mathrm{nM}$ (Kim et al., 2018). van Rodijnen et al., (2010) found only a slight difference in potency between candesartan and irbesartan, and their calculations estimate
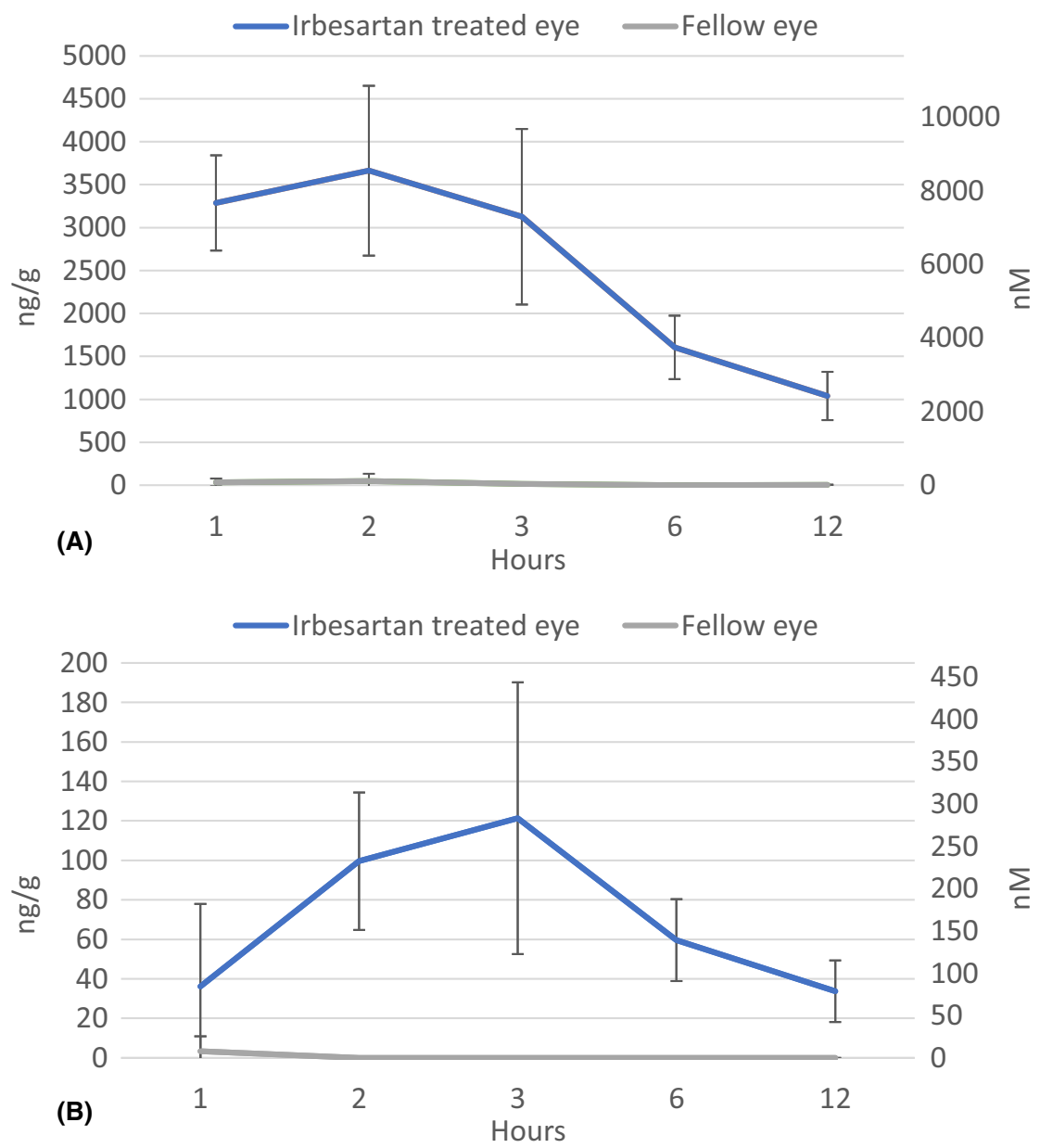

Fig. 2. A (top): irbesartan concentration $(n=26$, mean $\pm \mathrm{SD} ; \mathrm{ng} / \mathrm{g}$ and $\mathrm{nM})$ in the cornea. B (bottom): irbesartan concentration in the aqueous humour. Charts show drug concentration at time-points (hours) after administration. Study eyes are shown in blue and untreated fellow eyes are shown in grey. candesartan's IC50 values to be between 0.4 and $0.7 \mathrm{nM}$. Our results show a concentration in aqueous humour of 100 times the IC50, suggesting over $99 \%$ inhibition of the receptor for both drugs.

In a study by Lee et al., 30 rabbits received an intravitreal single injection of $1 \mathrm{mg}$ of candesartan and analysed the concentration in the vitreous at different time-points, calculating a halflife of candesartan of approximately $6.83 \mathrm{hr}$. In our study, the single dose administered to the rabbits was equal to $0.05 \mathrm{mg}$. Considering Lee et al. calculations and the difference in the routes of administration, the $48 \mathrm{hr}$ washout period we established between treatments is enough to eliminate residual drugs from previous administrations and avoid a cumulative effect. They also indicated that the common daily oral dose of candesartan for humans is $16 \mathrm{mg}$ and, compared with that, the intraocular concentration after a topical administration of a $0.5 \mathrm{mg}$ dose of candesartan is approximately 200 times higher than that after taking $16 \mathrm{mg}$ orally (Lee et al., 2011).

Several studies have been performed to determine the pharmacokinetic properties of $\gamma$-cyclodextrin/drug complexes after topical administration to the eye. In a study by Johannsdóttir et al., dexamethasone in cyclodextrin microsuspension was topically applied in rabbits to determine the pharmacokinetics. Their results showed a maximum concentration of $7506 \pm 1067 \mathrm{nM}$ in the cornea and $438 \pm 107 \mathrm{nM}$ in the aqueous humour $2 \mathrm{hr}$ after the administration (Johannsdottir et al., 2018). Our pharmacokinetic profiles for irbesartan and candesartan in the corneal tissue and aqueous humour are in general agreement with those reported by Johannsdottir et al. regarding dexamethasone, showing an increase of the drug concentration during the first $2-3 \mathrm{hr}$ after administration and a slow decrease after that. This similarity supports our hypothesis that cyclodextrin nanoparticle ensures a sustained release of the drug in the eye tissues and enables penetration of the drug to the anterior chamber.

The pharmacokinetic profiles observed with irbesartan and candesartan also coincide with data reported in previous studies by Djebli et al. and Mishima using different drugs, where 

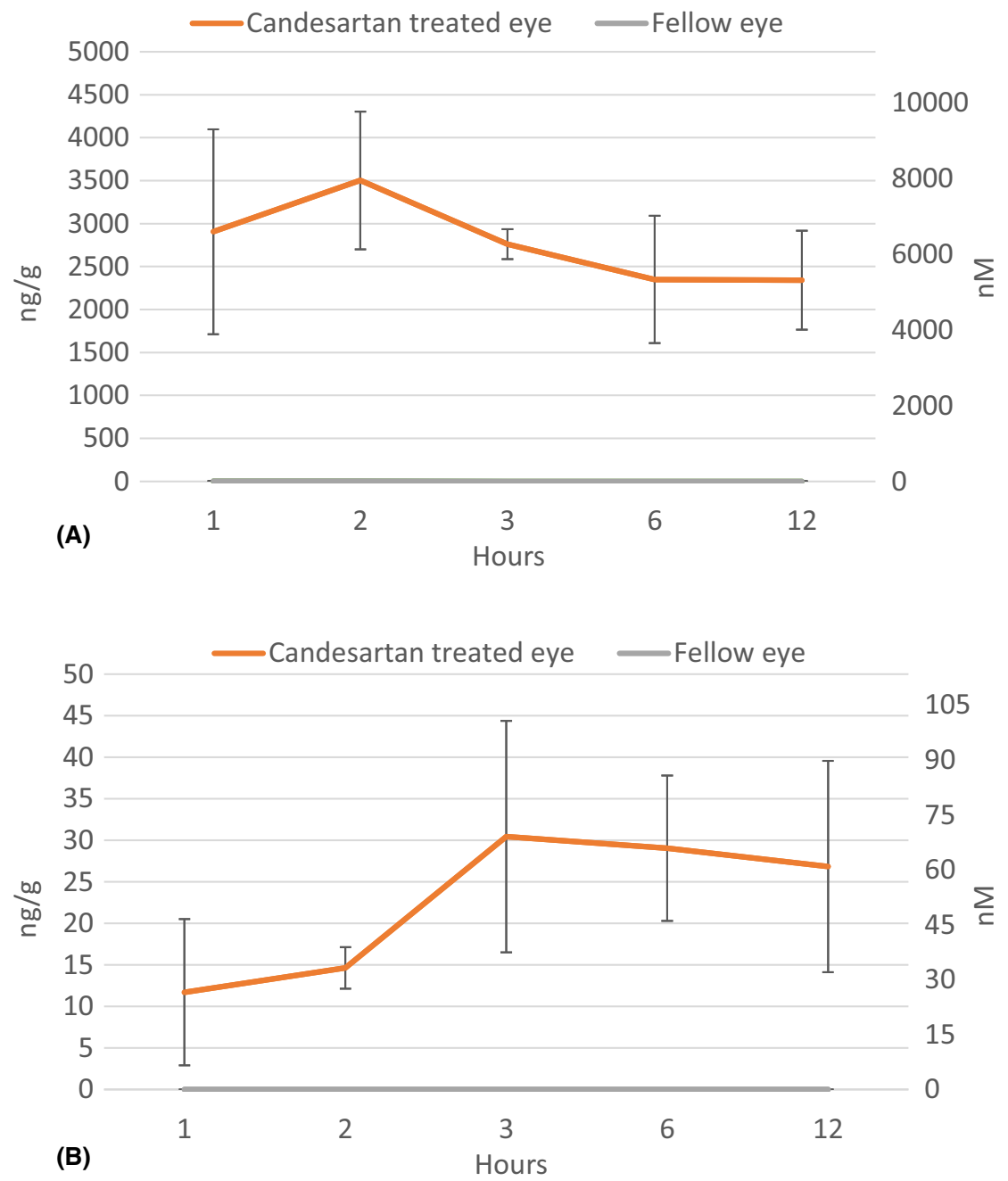

Fig. 3. A (top): candesartan concentration ( $n=23$, mean $\pm \mathrm{SD} ; \mathrm{ng} / \mathrm{g}$ and $\mathrm{nmol})$ in the cornea. B (bottom): candesartan concentration in the aqueous humour. Charts show drug concentration at time-points (hours) after administration. Study eyes are shown in orange and untreated fellow eyes are shown in grey.

the drug concentration follows a progressive decrease in the corneal tissue while it peaks in the aqueous humour around $2 \mathrm{hr}$ after administration
(Mishima, 1981; Djebli et al., 2017). As stated by Djebli et al., these findings are consistent with the physiology of the eye (i.e. aqueous humour being a fluid with a higher turnover compared to the cornea tissue). However, there are perceptible differences between the pharmacokinetic profiles of irbesartan and candesartan, the latter showing more stable and sustained drug concentrations in both cornea and aqueous humour throughout time. These results are consistent with those reported by van Rodijnen et al. that suggested a slower dissociation of candesartan from the AT1-receptor than irbesartan and losartan (van Rodijnen et al., 2010).

Chiang et al. tested different timolol preparations and measured the effect on the IOP in rabbits. Their results showed a noticeable decrease in the IOP $1 \mathrm{hr}$ after a $50 \mu \mathrm{l}$ administration of $0.5 \%$ timolol, which is consistent to our results where we can see that timolol is the group that shows the greatest decrease $2 \mathrm{hr}$ after the administration (Chiang et al., 1996).

In our study, a blank group was also monitored as a control for a diurnal effect and other variability, as both normal and glaucomatous human eyes can show considerable variation in intraocular pressure (Wilensky, 1991). Although a decreasing trend along the day was observed for the blank group in our study, this change did not reach statistical significance compared with the treated groups $(n=10, \mathrm{p}>0.05)$. According to Cervino et al., in addition to the circadian rhythm, IOP shortterm fluctuations are associated with heart rate, breathing patterns, eye or lid position or physical activity, as well as issues regarding repeatability and reproducibility of rebound tonometry (Shapiro et al., 2006). Other potential factors influencing IOP fluctuations

Table 1. List of published reports on the IOP-lowering effect of ARBs and ACEs using different experimental models and routes of administration

\begin{tabular}{|c|c|c|c|c|}
\hline Drug & References & $\begin{array}{l}\text { Route of } \\
\text { administration }\end{array}$ & Model & Effect \\
\hline SCH 33861 (ACE inhibitor) & Watkins RW et al., (1987) & Topical & Rabbits & $\begin{array}{l}\text { Well tolerated and effective in lowering intraocular } \\
\text { pressure in patients with ocular hypertension or primary } \\
\text { open-angle glaucoma. }\end{array}$ \\
\hline Captopril (ACE inhibitor) & Costagliola et al., (1995) & Oral & Human & $\begin{array}{l}\text { Significantly lowers IOP in all patients by increasing the } \\
\text { outflow of aqueous humour. }\end{array}$ \\
\hline $\begin{array}{l}\text { Enalaprilat nanoparticle } \\
\text { eye drops (ACE inhibitor) }\end{array}$ & Loftsson et al., (2010) & Topical & Rabbits & $\begin{array}{l}\text { The decrease in the IOP was proportional to the } \\
\text { concentration of the drug dissolved in the formulation. }\end{array}$ \\
\hline CS-088 (ARB) & Inoue et al., (2001) & Topical & Rabbits & IOP-lowering effect in two models of hypertensive rabbits. \\
\hline Losartan (ARB) & Iaccarino et al., (2002) & Oral & Human & $\begin{array}{l}\text { Decrease in the IOP in hypertensive humans mainly due to } \\
\text { a reduction in the production of aqueous humour. }\end{array}$ \\
\hline $\begin{array}{l}\text { Irbesartan and } \\
\text { Telmisartan (ARBs) }\end{array}$ & Hazlewood et al., (2018) & Oral & Human & $\begin{array}{l}\text { Both ARBs lower IOP and suggested that delivery of } \\
\text { ARBs by eye drops would help to achieve localized } \\
\text { effective drug concentrations. }\end{array}$ \\
\hline
\end{tabular}


such as water drinking, animal handling and drug administration must be considered. Brucculeri et al. observed that IOP increased significantly after water ingestion and remained altered for $45 \mathrm{~min}$ (Brucculeri et al., 1999).

Furthermore, Dinslage et al., (1998) studied the effect of animal handling on IOP, observing an increase followed by a decrease from the normal pressure for a period lasting from a few minutes to several hours. In our study, rebound tonometry requires handling each animal individually several times a day, however, rabbits were handled gently before IOP measurement to cause them minimal disturbances. As indicated by Ma et al., if any sign of stress was found, IOP measurements were postponed for at least another two minutes before repeating the measurements. Regarding water supply, we intended for the rabbits to have a continuous source of drinking water so fluid balance was not interrupted and minimal changes in IOP were caused due to water loading (Ma et al., 2016).

Although the outcome of the study was positive, it shows some potential limitations such as the small sample size of animals used in the IOP study. Individual values for IOP show variability that could affect the robustness of the statistical test and provide deviation in the analysis of the results. Another limitation is the duration of the IOP measurements, with the last one taken $4 \mathrm{hr}$ after the administration while pharmacokinetic data shows that drug can be detected in the tissues at least until $12 \mathrm{hr}$ after the administration.

\section{Conclusion}

Irbesartan and candesartan eye drops deliver drug into the eye in pharmacologically relevant concentration, achieving drug concentrations 100 times above the IC50 for angiotensin II receptor and showing an IOP-lowering effect. Our data suggest that both ARBs could have potential as a new class of eye drops to lower IOP in glaucoma. Clinical trials are needed to confirm and develop this thesis.

\section{References}

Agarwal R, Krasilnikova AV, Raja IS, Agarwal P \& Mohd Ismail N. Mechanisms of angiotensin converting enzyme inhibitor-induced IOP reduction in normotensive rats. Eur J Pharmacol 730: 8-13.

Al Sabbah Z, Mansoor A \& Kaul U (2013): Angiotensin receptor blockers - Advantages of the new sartans. J Assoc Physicians India 61(7): 464-470.

Brucculeri M, Hammel T, Harris A, Malinovsky V \& Martin B (1999): Regulation of intraocular pressure after water drinking. $\mathbf{J}$ Glaucoma 8(2): 111-116.

Brunner HR (2007): Angiotensin II receptor blockers. Compr Hypertens 75246: 10031017.

Campbell DJ (2014): Clinical relevance of local renin angiotensin systems. Front Endocrinol (Lausanne) 5(6): 1-5.

Chiang CH, Ho JI \& Chen JL (1996): Pharmacokinetics and intraocular pressure lowering effect of timolol preparations in rabbit eyes. J Ocul Pharmacol Ther 12(4): 471-480.

Costagliola C, Di Benedetto R, DeCaprio L, Verde R \& Mastropasqua R (1995): Effect of oral captopril (SQ 14225) on intraocular pressure in man. Eur J Ophthalmol 5(1): 19-25.

Dinslage S, McLaren J \& Brubaker R (1998): Intraocular pressure in rabbits by telemetry II: Effects of animal handling and drugs. Investig Ophthalmol Vis Sci 39(12): 24852489.

Djebli N, Khier S, Griguer F, Coutant AL, Tavernier A, Fabre G, Leriche C \& Fabre D (2017): Ocular drug distribution after topical administration: population pharmacokinetic model in rabbits. Eur J Drug Metab Pharmacokinet 42(1): 59-68.

Hazlewood RJ, Chen Q, Clark F, Kuchtey J \& Kuchtey RW (2018): Differential effects of angiotensin II type I receptor blockers on reducing intraocular pressure and TGF $\beta$ signaling in the mouse retina. PLoS One $\mathbf{1 3}$ (8): 1-18.

Holappa M, Vapaatalo H \& Vaajanen A (2020): Local ocular renin-angiotensin-aldosterone system: any connection with intraocular pressure? A comprehensive review. Ann Med 52(5): 191-206.

Iaccarino G, Mastropasqua L, Costagliola C, Leonarda De Rosa M, Ciancaglini M \& Verolino M (2002): Effect of oral losartan potassium administration on intraocularpressure in normotensive and glaucomatous human subjects. Exp Eye Res 71(2): 167-171.

Inoue K (2014): Managing adverse effects of glaucoma medications. Clin Ophthalmol 8 : 903-913.

Inoue T, Yokoyoma T, Mori Y, Sasaki Y, Hosokawa T, Yanagisawa H \& Koike H (2001): The effect of topical CS-088, an angiotensin AT1 receptor antagonist, on intraocular pressure and aqueous humor dynamics in rabbits. Curr Eye Res 23(2): 133-138.

Jansook P, Muankaew C, Stefánsson E \& Loftsson T (2015): Development of eye drops containing antihypertensive drugs: Formulation of aqueous irbesartan $/ \gamma C D$ eye drops. Pharm Dev Technol 20(5): 626632.
Johannsdottir S, Jansook P, Stefansson E et al. (2018): Topical drug delivery to the posterior segment of the eye: Dexamethasone concentrations in various eye tissues after topical administration for up to 15 days to rabbits. J Drug Deliv Sci Technol 45: 449 454.

Kim D, Pattamatta U, Kelly E, Healey PR, Carnt N, Zoellner H \& White AJR (2018): Inhibitory effects of angiotensin II receptor blockade on human tenon fibroblast migration and reactive oxygen species production in cell culture. Transl Vis Sci Technol 7(2): 20.

Lee JE, Lim DW, Park HJ, Shin JH, Lee SM \& Oum BS (2011): Intraocular toxicity and pharmacokinetics of candesartan in a rabbit model. Investig Ophthalmol Vis Sci 52(6): 2924-2929.

Loftsson T, Thorisdóttir S, Fridriksdóttir H \& Stefánsson E (2010): Enalaprilat and enalapril maleate eyedrops lower intraocular pressure in rabbits. Acta Ophthalmol 88(3): 337-341.

Ma D, Chen CB, Liang J, Lu Z, Chen H \& Zhang M (2016): Repeatability, reproducibility and agreement of intraocular pressure measurement in rabbits by the TonoVet and Tono-Pen. Sci Rep 6(10): 1-7.

Mishima S (1981): Clinical pharmacokinetics of the eye. Proctor lecture. Investig Ophthalmol Vis Sci 21(4): 504.

Muankaew C, Jansook P, Stefánsson E \& Loftsson T (2014): Effect of $\gamma$-cyclodextrin on solubilization and complexation of irbesartan: Influence of $\mathrm{pH}$ and excipients. Int $\mathbf{J}$ Pharm 474(1-2): 80-90.

Patel A, Cholkar K, Agrahari V \& Mitra AK (2013): Ocular drug delivery systems: An overview. World J Pharmacol 2(2): 47-64.

van Rodijnen WF, van Lambalgen TA, van Teijlingen ME, Tangelder G-J \& ter Wee PM (2010): Comparison of the AT1-receptor blockers candesartan, irbesartan and losartan for inhibiting renal microvascular constriction. J Renin-Angiotensin-Aldosterone Syst 2(1 suppl): S204-S210.

Shapiro B, Dickersin K \& Lietman T (2006): Trachoma, antibiotics and randomised controlled trials. Br J Ophthalmol 90(12): 14431444.

Van Haeringen N (1996): The renin-angiotensin. Br J Ophthalmol 80(2): 99-100.

Watkins RWBaum T, Cedeno K, Smith EM, Yuen PH, Ahn HS, \& Barnett A (1987): Topical ocular hypotensive effects of the novel angiotensin converting enzyme inhibitor SCH 33861 in conscious rabbits. J Ocul Pharmacol 3(4): 295-307.

Wilensky JT (1991): Diurnal variations in intraocular pressure. Trans Am Ophthalmol Soc 89: 757-790.

Received on March 11th, 2020.

Accepted on September 8th, 2020.

Correspondence:

Laura Lorenzo-Soler, MSc 
Faculty of Medicine

University of Iceland

Vatnsmýrarvegur 16

101 Reykjavík

Phone: +354 7677313

Email: 1ls10@hi.is

We thank Martin Kallab and Kornelia Schützenberger for their help in performing the PK experiments. Further, the support of the Department of Biomedical Research, Medical University of Vienna is gratefully acknowledged.

The following author(s) indicated a financial or other interest:

Employment or Leadership Position: Olof B. Olafsdottir, Iris M. Kristinsdottir, Aimin Tan.
Stock Ownership: Thorsteinn Loftsson, Einar Stefansson.

This study has received partial funding from the European Union's programme Eurostar under the project No PREVIN E1 1008 and the Horizon 2020 research and innovation programme under the Marie Sklodowska-Curie grant agreement No 765441. 